\title{
FUTEBOL: UMA INVESTIGAÇÃO DO ESTADO DO CONHECIMENTO DAS DISSERTAÇÕES E TESES PRODUZIDAS NO BRASIL
}

\author{
Alex Fensterseifer \\ Universidade Federal de Santa Catarina, Florianópolis, Santa Catarina, Brasil. \\ Michel Angillo Saad \\ Universidade Federal de Santa Catarina, Florianópolis, Santa Catarina, Brasil. \\ Antônio Renato Pereira Moro \\ Universidade Federal de Santa Catarina, Florianópolis, Santa Catarina, Brasil.
}

\begin{abstract}
Resumo
Objetivo: Investigar e analisar o estado do conhecimento das dissertações e teses produzidas no Brasil sobre a temática do futebol disponíveis no banco de teses da CAPES de 1987 a 2014. A pesquisa realiza: busca, recuperação e preparação dos dados, tratamento estatístico, representação gráfica e interpretação dos dados. Os resultados mostram que o futebol é investigado pelas nove grandes áreas e por 84 áreas do conhecimento. A maior frequência dos estudos é sobre torcidas organizadas e Copa do Mundo. Os resultados indicam também que 82,8\% das pesquisas se concentram nas Ciências da Saúde, Humanas e Sociais Aplicadas. Nas análises gerais o futebol produziu um conhecimento científico robusto com recorrência e fragmentação.
\end{abstract}

Palavras-chave: Futebol. Conhecimento. Teses. Dissertações.

\section{Introdução}

O conhecimento tem papel fundamental na vida da humanidade e na relação da sociedade com a natureza. Para se sustentar e conquistar sua existência, a humanidade precisa dominar a natureza e transformá-la, o que só é possível com o conhecimento do universo que a cerca. A necessidade de encontrar respostas para problemas cada vez mais complexos exige análise da produção do conhecimento (OLIVEIRA, 2011).

Para Megid Neto e Pacheco (2001), avaliar o estado do conhecimento da pesquisa tem como objetivo realçar determinado período para poder analisar o desenvolvimento, as principais temáticas, as áreas não investigadas e quais caminhos podem ser traçados com base nos estudos. Madeira (2012) entende que a pesquisa sobre o estado do conhecimento tem a vantagem de possibilitar que o pesquisador reúna grande número de fenômenos, agrupando, quando necessário, informações que talvez estivessem perdidas no espaço ou nas bibliotecas.

O foco da pesquisa - futebol - é um fenômeno cultural brasileiro que envolve milhões de pessoas e é capaz de influenciar seu comportamento. Pelo significado do futebol na cultura brasileira e sua influência no cenário nacional e internacional, é importante saber o que está sendo estudado sobre esse esporte.

A importância que vem sendo atribuída ao futebol nos dois últimos séculos no cenário mundial, especialmente no contexto brasileiro, inspirou as pesquisas nas diferentes áreas do 
conhecimento, como, por exemplo: Educação Física, Sociologia, Antropologia, História, Geografia, Administração, Comunicação Social e Economia, dentre outros campos de conhecimento (SOUZA; ALMEIDA; MARCHI JÚNIOR, 2014).

O presente estudo se justifica igualmente porque conhecer os caminhos da produção da ciência é importante para a qualidade das investigações, para o desenvolvimento do conhecimento e avaliação da produção no âmbito social. A procura dos porquês dos rumos escolhidos pelos estudos possibilita mostrar os avanços, indicar áreas deficientes e construir diferentes possibilidades de investigar o conhecimento.

Diante do contexto apresentado, o estudo tem como objetivo investigar o estado do conhecimento em futebol no âmbito das dissertações e teses defendidas no Brasil, tendo como recorte o período de 1987 a 2014.

\section{Material e Método}

O método foi construído com base em estudos que investigaram a análise da produção do conhecimento, teses e dissertações defendidas nos programas de pós-graduação do Brasil nos últimos anos, destacando-se algumas teses e dissertações que serviram para delimitar a fundamentação teórica e o escopo metodológico deste estudo, como: Vieira (2011), Cadamuro (2011), Igami (2012), Carvalho (2012), Miranda (2012) e Sacardo (2012).

Nesta pesquisa trabalhou-se com o banco de teses da CAPES, com as dissertações de mestrado e teses de doutorado defendidas em programas de pós-graduação no Brasil que abordam o tema futebol. Fizeram parte da investigação todas as áreas do conhecimento que apresentassem trabalhos sobre o futebol.

Foi realizada na internet uma busca por teses e dissertações disponíveis no banco de teses da CAPES utilizando a palavra "futebol", tendo sido encontrados 1.591 estudos (teses e dissertações) que investigaram esse tema; foram salvas todas as teses e dissertações e colocadas numa planilha do Excel; na planilha foram colocados os seguintes indicadores: autor, título da tese ou dissertação, grandes áreas, área do conhecimento, ano da publicação, nível (doutorado ou mestrado), estado, temáticas e método quanto à abordagem do problema. De posse do material, foram realizadas duas leituras dos títulos e resumos de todas as teses e dissertações no banco de teses da CAPES para selecionar os trabalhos consentâneos com os objetivos da pesquisa; durante a leitura e releitura dos resumos das teses e dissertações, foi verificada a necessidade de excluir estudos que não se relacionavam com a temática futebol ou que eram duplicados. Nessa seleção dos trabalhos foram excluídos 333 estudos, ficando para análise 1.258 teses e dissertações.

As teses e dissertações foram selecionadas obedecendo aos seguintes critérios de inclusão: teses e dissertações que tinham a palavra futebol no título; que tinham como objetivo principal a temática futebol; que utilizaram jogadores de futebol para investigação; em que um dos objetivos era o futebol; que apresentam elementos relacionados ao futebol (torcedores, equipamentos, software, literatura e outros). Os estudos excluídos da investigação foram: teses e dissertações que trabalhavam com futsal; que trabalhavam com futebol de robôs; com a palavra futebol no resumo, mas não era objeto de estudo; que trabalhavam com futevôlei; que pesquisaram sobre o futebol para cegos ou futebol de cinco.

A análise dos dados foi desenvolvida nos seguintes procedimentos: realização da busca, recuperação e preparação dos dados, tratamento estatístico, representação gráfica e interpretação dos gráficos (CARVALHO, 2012). Dentro dessas etapas, foram definidos os objetivos da análise, identificando o que se quer com as medidas, definindo os mecanismos de coleta dos dados, estabelecendo estratégias de busca de informação para coleta de dados, identificação, localização, acesso às fontes de informação, conferindo as medidas disponíveis, constituindo relacionamentos entre os dados obtidos e a confiabilidade das informações (SILVA; 
HAYASHI; HAYASHI, 2011). Com o objetivo de facilitar a interpretação dos dados, essa investigação dividiu o estudo conforme as grandes áreas do conhecimento (9), que foram construídas baseadas no modelo apresentado pela CAPES (2012) (Tabela de áreas do conhecimento), com o objetivo de buscar uma maior afinidade entre as áreas.

\section{Resultados e Discussões}

\section{Distribuição dos estudos por grandes áreas do conhecimento}

A distribuição por grandes áreas do conhecimento mostrou que existe interesse em estudar o futebol em todas essas áreas. Esse espectro mostra e reforça a importância que o futebol exerce na sociedade brasileira, como ilustra a Tabela 1.

Tabela 1 - Distribuição das teses e dissertações por grandes áreas do conhecimento

\begin{tabular}{l|l|l|l|l} 
GRANDES ÁREAS & Mestrado & Doutorado & Total & $\mathbf{\%}$ \\
\hline Ciências da Saúde & 369 & 71 & 440 & $35 \%$ \\
\hline Ciências Humanas & $\mathbf{2 6 1}$ & $\mathbf{7 7}$ & $\mathbf{3 3 8}$ & $\mathbf{2 7 \%}$ \\
\hline Ciências Sociais Aplicadas & 231 & 33 & 264 & $21 \%$ \\
\hline Linguísticas Letras e Artes & $\mathbf{5 1}$ & $\mathbf{1 6}$ & $\mathbf{6 7}$ & $\mathbf{5 \%}$ \\
\hline Engenharias & 37 & 10 & 47 & $4 \%$ \\
\hline Multidisciplinar & $\mathbf{3 6}$ & $\mathbf{7}$ & $\mathbf{4 3}$ & $\mathbf{3 \%}$ \\
\hline Ciências Exatas e da Terra & 21 & 7 & 28 & $2 \%$ \\
\hline Ciências Biológica & $\mathbf{1 5}$ & $\mathbf{7}$ & $\mathbf{2 2}$ & $\mathbf{2 \%}$ \\
\hline Ciências Agrárias & 6 & 3 & 9 & $1 \%$ \\
\hline TOTAL & $\mathbf{1 0 2 7}$ & $\mathbf{2 3 1}$ & $\mathbf{1 2 5 8}$ & $\mathbf{1 0 0} \%$
\end{tabular}

Fonte: Elaborada pelos autores com dados do banco de teses da CAPES, 2016.

Os dados da Tabela 1 mostram o relacionamento com todas as grandes áreas do conhecimento e os números e percentuais de dissertações e teses nas diferentes grandes áreas. Por isso, o futebol é um fenômeno de estudo multidisciplinar, com grande abrangência nas temáticas abordadas e que recorre a todas as grandes áreas do conhecimento para explicar seu campo científico, na busca por melhor entendimento das suas especificidades e do contexto social onde se insere. Os resultados mostram a concentração dos estudos nas Ciências da Saúde, Humanas e Sociais Aplicadas, mas todas as outras grandes áreas têm uma produção científica significativa e importante para o futebol. Os dados deste estudo mostram ainda que as pesquisas estão presentes em nível de mestrado e doutorado em todas as grandes áreas, o que é positivo para o desenvolvimento desse campo científico. Também os percentuais de pesquisas nos cursos de mestrado podem apontar um percentual favorável para sua continuidade no nível seguinte, o doutorado.

Compulsando a literatura, verifica-se que no seu artigo, Giglio e Spaggiari (2010) expuseram o futebol amparado por referenciais das Ciências Humanas, enquanto Andrade e Ramos (2015) indicam que nas revistas científicas predominam as Ciências Sociais.

As outras grandes áreas: Linguística, Letras e Artes, Engenharia, Ciências Exatas e da Terra, Ciências Biológicas e Ciências Agrárias, que parecem mais distantes, também mostraram interesse em investigar o futebol, com número menor de ocorrências, mas significativos para as pesquisas que tratam do assunto.

Embora possam ser feitas muitas interpretações a respeito das grandes áreas do conhecimento, a mais óbvia é que existe uma fragmentação do conhecimento produzido sobre futebol. A questão da fragmentação é trabalhada por diferentes autores, como: Nascimento; Santiago (2012) e Oliveira (2011). Para este último, é inegável que a construção do conhecimento 
foi herdada de forma fragmentada, devido às características históricas da construção da ciência. E também que as áreas de maior presença são as que mantêm maiores e mais estreitos vínculos disciplinares dentro dos programas de pós-graduação.

\section{Distribuição dos estudos por áreas do conhecimento}

O estudo analisou também as áreas que são um conjunto de informações e referenciais que mantêm afinidades de complementaridade recíproca. $\mathrm{O}$ presente estudo encontrou 84 áreas que investigaram o futebol, das quais 20 se destacaram com maior frequência (Freq.) de estudos, como se vê na Tabela 2 a seguir.

Tabela 2 - Distribuição das 20 primeiras áreas do conhecimento

\begin{tabular}{l|ll|l|ll} 
Áreas dos estudos & Freq. & $\mathbf{\%}$ & Áreas dos estudos & \multicolumn{2}{l}{ Freq. $\%$} \\
\hline Educação Física & 329 & $26,15 \%$ & Interdisciplinares & 30 & $2,38 \%$ \\
\hline História & 96 & $7,63 \%$ & Direito & 29 & $2,30 \%$ \\
\hline Comunicação & 88 & $6,99 \%$ & Fisioterapia Terapia ocupacional & 20 & $1,58 \%$ \\
\hline Administração & 85 & $6,75 \%$ & Linguística & 18 & $1,43 \%$ \\
\hline Sociologia & 78 & $6,20 \%$ & Ciência da Informação & 16 & $1,27 \%$ \\
\hline Psicologia & 50 & $3,97 \%$ & Nutrição & 15 & $1,19 \%$ \\
\hline Educação & 46 & $3,65 \%$ & Sociais e Humanidade & 14 & $1,11 \%$ \\
\hline Letras & 41 & $3,25 \%$ & Engenharia de Produção & 13 & $1,03 \%$ \\
\hline Medicina & 39 & $3,10 \%$ & Geografia & 13 & $1,03 \%$ \\
\hline Antropologia & 33 & $2,62 \%$ & Arquitetura e Urbanismo & 11 & $0,87 \%$ \\
\hline & & & TOTAL & $\mathbf{1 0 6 9} \mathbf{8 4 , 9 7 \%}$
\end{tabular}

Fonte: Elaborada pelos autores com dados do banco de teses da CAPES, 2016.

Em outras 64 áreas, não menos importantes, foram encontrados 189 (15,02\%) estudos: Engenharia Biomédica, Engenharia Elétrica, Fisiologia, Saúde e Biológicas, Bioquímica, Teologia, Engenharia Civil, Engenharia Mecânica, Ciência Política, Cirurgia, Planejamento Urbano e Regional, Ciência e Tecnologia de Alimentos, Clínica Médica, Saúde Coletiva, Desenho Industrial, Administração de Empresas, Odontologia, Economia, Turismo, Ciências Contábeis, Ensino, Biologia Geral, Ortopedia, Matemática, Ciência de Alimentos, Agronomia, Biotecnologia, Genética, Educação de Adultos, Língua Portuguesa, Literatura Brasileira, Artes, Enfermagem, Pediatria, Anatomia Patológica e Patologia Clínica, Cardiologia, Química, Probabilidade e Estatística, Física, Ciência da Informação, Engenharia de Materiais e Metalúrgica, Engenharia Sanitária, Engenharia de Tecnologia e Gestão, Morfologia, Planejamento Educacional, Psicologia do Ensino e da Aprendizagem, Psicologia Social, História do Brasil, História Regional do Brasil, Relações Internacionais Bilaterais e Multilaterais, Psicobiologia, Teoria da Literatura, Linguística Aplicada, Epidemiologia, Farmacologia, Fonoaudiologia, Doenças Infecciosas e Parasitárias, Psiquiatria, Radiologia Médica, Direito Público, Sociologia Específica, Serviço Social e Estatística.

Importante observar nos dados o grande número de áreas do conhecimento que estudaram o futebol, concentrando a maioria dos estudos em vinte áreas do conhecimento, que equivalem a 84,97\% das dissertações e teses defendidas. As áreas com números mais elevados de investigações envolvem oito grandes áreas do conhecimento com boa distribuição dos estudos entre si.

As áreas que pesquisam o futebol são excelentes indicadoras de como está sendo construído o saber: elas identificam os temas, os problemas, as bases teóricas e metodológicas de como cada área trata o conhecimento científico. A variedade das áreas que pesquisam sobre o futebol tem sido observada por estudos de outras áreas, como Giglio e Spaggiari (2010), Nebreda et al. (2015), repercutindo nas diferentes áreas do conhecimento que buscam investigar 
o tema. Essas investigações mostram o quanto um objeto de estudo - o futebol - desperta interesse de diferentes áreas de conhecimento com objetivos e natureza diferentes, em busca de interpretar esse fenômeno cultural. Permite também inferir que o conhecimento fragmentado em alguns momentos pode ser único, respeitando as suas diversidades, faltando um elo de comunicação entre as áreas.

Por outro lado, existe um excesso de áreas, aspecto negativo que reforça cada vez mais a fragmentação da ciência, gerando diversas concepções que muitas vezes se repetem, porque não existe comunicação, diálogo, troca de conhecimentos entre as áreas: cada pesquisador produz no seu grupo.

A resposta a essa curiosidade de investigação sobre o futebol pelas diferentes áreas do conhecimento é provavelmente devido à importância do futebol na cultura e na sociedade brasileira, descrita por Giulianotti (2002); Souza, Almeida e Marchi Júnior (2014). A realização da Copa do Mundo no Brasil pode ter acentuado o interesse, aumentando o número de investigações sobre o futebol. O grande investimento para a Copa do Mundo pode também ter aumentado os recursos para pesquisar sobre o futebol. Esse maior investimento da CAPES em bolsas e fomento - em 2008 eram 218.943, saltando para 540.693 em 2012 - mostra aumento de mais de $100 \%$ nos investimentos para pesquisa (CAPES, 2014).

\section{Distribuição das principais temáticas abordadas}

A análise aqui apresentada mostrou as principais características das teses e dissertações sobre o futebol na pós-graduação brasileira. É importante salientar que foi encontrada grande variedade de temáticas nos estudos sobre o futebol, devido ao grande número de estudos e áreas que estudaram esse tema. A Tabela 3 mostra essa situação por número de ocorrências.

Tabela 3 - Frequência das principais temáticas estudadas

\begin{tabular}{l|l} 
Temáticas Mestrado/Doutorado & Freq. \\
\hline Torcidas organizadas & $\mathbf{6 8}$ \\
\hline Copa do Mundo & $\mathbf{5 3}$ \\
\hline Identidade nacional e cultural & $\mathbf{4 2}$ \\
\hline Clubes de futebol & $\mathbf{3 4}$ \\
\hline Mídia e jornalismo & $\mathbf{2 8}$ \\
\hline Administração/gestão & $\mathbf{2 3}$ \\
\hline Estádios de futebol & $\mathbf{2 2}$ \\
\hline Marketing & $\mathbf{1 8}$ \\
\hline Nelson Rodrigues & $\mathbf{1 7}$ \\
\hline Histórias do futebol & $\mathbf{1 7}$
\end{tabular}

Fonte: Elaborada pelo autor com dados do banco de teses da CAPES, 2016.

Conforme os resultados da Tabela 3, primeiramente destaca-se que as 10 temáticas com maior número de ocorrências nas dissertações e teses foram: torcidas organizadas, Copa do Mundo, identidade do futebol, clubes de futebol, mídia e jornalismo, administração e gestão, estádios de futebol, marketing, o escritor e jornalista Nelson Rodrigues e histórias do futebol. As 10 principais temáticas somam 322, que representam $25,59 \%$ do total de dissertações e teses defendidas na pós-graduação brasileira sobre futebol.

O ponto negativo talvez seja o grande número de estudos repetidos, provavelmente porque não existe comunicação entre as áreas: cada pesquisador realiza sua pesquisa nos seus grupos e universidades. Por outro lado, talvez possa representar fortalecimento e amadureci- 
mento teórico das discussões sobre determinadas temáticas. Portanto, essa situação merece novos estudos para aprofundar a questão.

As temáticas abordadas nas dissertações e teses mostraram um campo de estudo abrangente, permitindo que sejam feitas adequações e mudanças com objetivo de melhorar a organização do foco temático das pesquisas.

Outro aspecto observado no universo de todas as temáticas estudadas é a multiplicidade de temas, evidenciando a amplitude do campo de estudo e a grande capacidade de desenvolvimento de novas pesquisas sobre o futebol. Também essa multiplicidade e o grande número de pesquisas com diferentes temáticas pode ser uma ótima orientação para futuras pesquisas sobre o futebol.

\section{Distribuição dos estudos pelo método de abordagem do problema}

A análise dos dados deste estudo (Banco de Teses da CAPES) mostrou que as pesquisas qualitativas são 809 (64\%), quantitativas 313 (25\%) e qualiquantitativas 136 (11\%), mostrando uma hegemonia no número de estudos das pesquisas qualitativas.

A maioria das pesquisas é qualitativa porque áreas como Linguística, Letras e Artes, e Ciências Humanas utilizam quase exclusivamente a pesquisa qualitativa, e nesta investigação a maioria dos estudos sobre futebol das dissertações e teses analisadas partiram da área das humanas.

A pesquisa quantitativa consegue um espaço maior nas áreas da Ciência da Saúde, Biológicas, Exatas e da Terra e Engenharia, áreas em que as pesquisas com esse método de abordagem superam o método qualitativo. Já a pesquisa qualiquantitativa encontra espaço em quase todas as grandes áreas do conhecimento, com destaque para as grandes áreas de Ciências Exatas e da Terra, Agrárias e Biológicas, não tendo sido encontrados estudos somente na Linguística, Letras e Artes.

Numa análise geral dos dados, verificou-se que as pesquisas qualitativas sobre futebol procuram uma percepção global dos estudos, com abordagens fenomenológica, hermenêutica e outras, utilizando levantamentos bibliográficos e análises documentais, entrevistas, questionários e observações.

Nas pesquisas quantitativas sobre o futebol houve preponderância de concepções tecnicistas, dados descritos com suporte da estatística, utilizando instrumentos para medições antropométricas, protocolos de observação, anamneses, avaliações e testes.

\section{Distribuição dos principais estudos por estados}

A distribuição das dissertações e teses por estado mostraram as desigualdades brasileiras, como se vê no Gráfico 1 a seguir. 
Gráfico 1 - Frequência das dissertações e teses por estados brasileiros

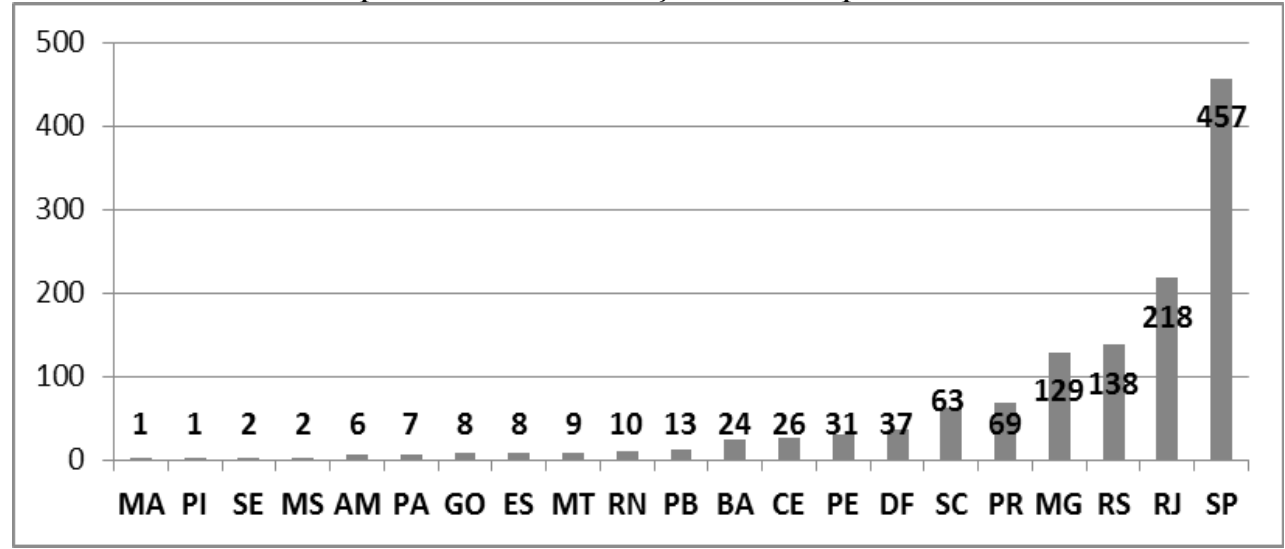

Fonte: Elaborada pelo autor com dados do banco de teses da CAPES, 2016.

Na Região Norte foi encontrada a maior desigualdade, não aparecendo pesquisa em cinco estados: Tocantins, Roraima, Acre, Amapá e Rondônia. Até 1998, nestes estados não havia mestrado ou doutorado disponível para a população (CAPES, 2014). Na Região Nordeste foram encontrados estudos em todos os estados, mas concentrados em cinco: Pernambuco, Ceará, Bahia, Paraíba e Rio Grande do Norte. Uma discrepância gritante entre os estados no número de pesquisas se revela nos dados: todos os estudos da Região Norte, Centro-Oeste, Nordeste e Sul somados atingem 450, ficando atrás do estado de São Paulo, com 457 dissertações e teses defendidas em seus estabelecimentos de ensino superior. Essa discrepância entre os estados também é observada em pesquisas que trabalharam com futebol, como Giglio e Spaggiari (2010) e de outras áreas do conhecimento, como Cadamuro (2011) e Vieira (2011).

Embora se observe crescimento nos estados brasileiros com menor número de estudos, ainda não é suficiente para modificar as grandes diferenças entre as regiões e estados brasileiros. Entre os motivos para essas discrepâncias (CAPES, 2014), reside o fato de que os programas de pós-graduação dos estados do Sudeste são mais antigos, a população é maior e existem mais recursos financeiros e humanos.

\section{Distribuição das dissertações e teses por ano de defesa}

A história do futebol no Brasil até o final dos anos 70 era escrita fora da academia, principalmente por ex-atletas e jornalistas. Passando esse período surgiu o interesse das Ciências Sociais e Humanas, atraindo num primeiro momento a atenção dos sociólogos e antropólogos, e posteriormente dos historiadores (SANTOS; DRUMOND, 2012).

A análise se baseia na comparação entre mestrado e doutorado, mostrando o crescimento dos dois níveis, como pode ser visto no Gráfico 2: 
Gráfico 2 - Frequência das dissertações e teses por ano de defesa

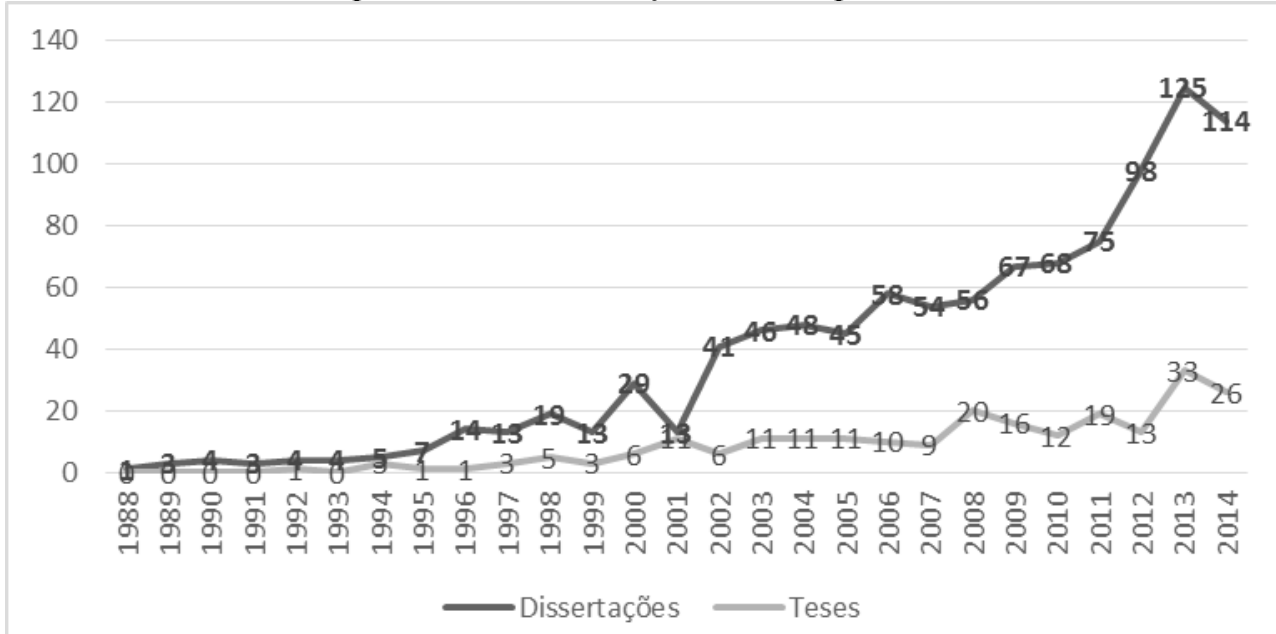

Fonte: Elaborado pelo autor com dados do banco de teses da CAPES, 2016.

Nos primeiros anos do mestrado - 1988 a 1999 - inicia-se o crescimento, apesar do número reduzido de dissertações (90), que corresponde a $8,75 \%$ dos estudos e produção média de 7,5 trabalhos por ano. Na primeira década do terceiro milênio - anos 2000 a 2010 ocorre um grande salto no número das dissertações e teses: durante esse espaço de tempo (11 anos) são defendidas 525 dissertações, o que representa 51,11\% e uma média de 47,72 estudos do total produzido no período analisado. O período seguinte, 2011 a 2014, em um espaço de tempo bem menor (4 anos) são defendidas 412 dissertações com a média anual de 103 estudos, caracterizando-se como o mais produtivo se considerarmos a correlação espaço/tempo de $40,11 \%$ em quatro anos.

No doutorado, no período entre 1988 e 2000, foram defendidas somente 23 teses (9,95\%); o segundo momento de crescimento ocorre de 2001 a 2007, com 69 teses $(29,87 \%)$; mas o ápice das teses que trabalharam com futebol aconteceria entre 2008 e 2014, com 139 teses defendidas $(60,17 \%)$.

O que pode ter contribuído para o processo de expansão dos estudos na pós-graduação brasileira foi porque cresceu o número de mestrados e doutorados: em 1998 era de 1259; em 2008, uma década depois, era de 2567; e em 2014 saltou para 3678; esse crescimento se deu muito principalmente pelo aumento de bolsas, financiamentos para as investigações e mecanismos de pressão da CAPES por produtividade das universidades. Este conjunto de fatores foram decisivos para alavancar o crescimento e o desenvolvimento da pós-graduação brasileira em termos quantitativos (CAPES, 2014), dando, como consequência, o aumento de teses e dissertações (COUTINHO et al., 2012).

\section{Distribuição das dissertações e teses por nível de qualificação}

$\mathrm{Na}$ distribuição das teses e dissertações sobre futebol ao longo dos últimos 29 anos, os dados deste estudo mostraram que o mestrado produziu $1027(81,63 \%)$ e o doutorado 231 $(18,36 \%)$, o que reflete a maneira como foi construída a pós-graduação no Brasil: primeiro a consolidação dos programas de mestrado e posteriormente a criação dos doutorados.

Os números são semelhantes aos das investigações de Giglio e Spaggiriari (2010). Em outras áreas do conhecimento, o quadro também se repete, como nos estudos de Vieira (2011), Cadamuro (2012) e CAPES (2014), que abrangem todos os programas do Brasil.

No nível de qualificação dos estudos deve-se levar em consideração, como ensina Cadamuro (2011), a expansão desordenada dos cursos de pós-graduação durante os anos 70 e 80 , 
principalmente dos mestrados, que acabou influenciando a produção científica brasileira, resultando no crescimento das dissertações contra o número reduzido de teses de doutorado.

Prosseguindo com Cadamuro, o crescimento do doutorado começa a ganhar espaço na produção científica quando o mestrado passa a ser insuficiente no processo de formação e qualificação dos professores, momento em que começam a consolidar-se os programas de pós-graduação brasileiros, contribuindo para o fortalecimento das diferentes áreas do conhecimento e atuação dos mestres e doutores no ensino superior e na pós-graduação. Por outro lado, Sacardo (2012) informa que embora aumente o número de estudos, a oferta de bolsas não supre a demanda dos programas de pós-graduação nas diversas áreas do conhecimento.

\section{Conclusões}

A sistematização das informações dos estudos permitiu identificar as problemáticas dos estudos sobre futebol, mas principalmente de situar o que foi produzido sobre o futebol, elemento fundamental para qualquer área que pretenda desenvolver-se e atingir um nível de qualidade na produção científica. Nenhuma área do conhecimento pode crescer, desenvolver-se e consolidar-se no meio científico acadêmico se não sistematizar o conhecimento que foi produzido no seu universo de pesquisa.

O mapeamento dos estudos feito nesta pesquisa indicou: que a produção científica sobre o futebol vem crescendo no país nos últimos anos; que existem muitas pesquisas e são crescentes os investimentos no seu desenvolvimento; e, finalmente, mostrou o caráter multidisciplinar do futebol, com todas as grandes áreas do conhecimento participando na construção do conhecimento científico sobre esse tema, faltando aos pesquisadores, ao conhecer o estado do conhecimento, articular-se com as diferentes áreas no intuito de contribuir para seu desenvolvimento. Além disso, as dissertações e teses mostraram como é grande o leque de possibilidades de investigação, reforçando o valor que o futebol tem na ciência, na pesquisa e na sociedade brasileira.

Outro aspecto foram as nove grandes áreas do conhecimento, em que as Ciências da Saúde, Humanas e Sociais Aplicadas concentraram a maioria dos estudos. Dentro das áreas, é importante destacar também a grande ocorrência de estudos sobre futebol na Educação Física, que era uma questão esperada, mas áreas como a História, Administração, Comunicação, Sociologia, Psicologia, Letras também tiveram interesse significativo e relevante para a produção do conhecimento sobre o futebol. Por outro lado, cabe destacar também o interesse em estudar o futebol por grandes áreas que poderiam ser consideradas mais distantes, como Letras, Engenharias, Ciências Agrárias e outras, mostrando como é multidisciplinar o interesse por estudar esse esporte. Essas questões reforçam ainda mais o âmbito multidisciplinar das pesquisas sobre o futebol.

Na questão da localização geográfica dos estudos, o tema futebol está presente em todas as regiões brasileiras, mas o grande problema verificado aqui foi a concentração dos estudos, principalmente na Região Sudeste e no estado de São Paulo, sendo necessário que o governo federal, programas de pós-graduação e orientadores invistam no desenvolvimento das regiões e estados onde a produtividade das pesquisas é pequena.

Também foi analisada neste estudo a questão temporal das dissertações e teses, que mostrou um crescimento constante da produção científica e um aumento das pesquisas em termos quantitativos nos últimos anos, influenciado certamente pelo evento Copa do Mundo 2014 de futebol e pelo aumento dos investimentos. Nesse aspecto, seria interessante analisar nos próximos estudos se esse crescimento continua, apesar do fracasso brasileiro na Copa do Mundo e da redução dos investimentos devido à crise política, social e econômica do Brasil. Já no nível de qualificação das teses e dissertações, o predomínio é do mestrado, o que acaba influenciando o nível da fundamentação das investigações, porque os doutorados exigem re- 
flexões e revisões com maior profundidade que os mestrados. Por outro lado, existe um potencial de crescimento do doutorado pelo grande número de pesquisadores de mestrado, mas é preciso verificar nos novos estudos se tal situação vai materializar-se futuramente no aumento de produtividade e na qualidade das teses.

Nas análises gerais o futebol produziu um conhecimento científico robusto, com certa recorrência e fragmentação. Além disso, analisar a produção científica num campo de conhecimento como o futebol possibilitou realizar uma avaliação da produção científica em determinada época, apontando indicativos que poderão ajudar no avanço científico desse esporte. Ao mesmo tempo os resultados deste estudo indicam que o uso da interdisciplinaridade para produzir conhecimento sobre futebol não é uma tendência, mas uma necessidade; a interdisciplinaridade da produção do conhecimento é um processo em construção, principalmente para aqueles que procuram lutar contra os desafios impostos pela fragmentação da ciência. Mas, essa é uma questão para discutir em outro momento.

\title{
FOOTBALL: AN INVESTIGATION ON THE STATE OF THE KNOWLEDGE OF DISSERTATIONS AND THESIS IN BRAZIL
}

\begin{abstract}
Objective: The study investigates and analyses the state of knowledge of dissertations and thesis about football produced in Brazil from 1987 to 2014 that are available at the CAPES thesis bank. Research carries out: Completion of the search, recovery and data preparation, statistical analysis, graphical representation and interpretation of data. The results state: football is investigated by the 9 great areas and by the 84 areas of knowledge. The highest frequency of studies is about football fan groups and the World Cup. The results indicate, yet, that $82 \%$ of the research is within the areas of Health Science, Humanities, and Applied Social Science. In general analysis, football has produced robust scientific knowledge with recurrence and fragmentation.
\end{abstract}

Keywords: Football. Knowledge. Theses. Dissertations.

\section{FÚTBOL: UNA INVESTIGACIÓN SOBRE EL ESTADO DE LOS CONOCIMIEN- TOS DE LAS DISERTACIONES Y TESIS PRODUCIDAS EN BRASIL}

\begin{abstract}
Resumen
Objetivo: Investigar y analizar el estado de los conocimientos de las disertaciones y tesis producidas en Brasil el tema del fútbol disponible en la base de datos de tesis de la CAPES 19872014. La investigación realiza un: búsqueda, recuperación y preparación de datos, análisis estadístico, representación gráfica e interpretación de datos. Los resultados muestran que el fútbol es investigado por 9 grandes áreas y 84 áreas de conocimiento. La mayor frecuencia de los estudios se organiza sobre hinchada y Copa Mundial. Los resultados también indican que el $82,8 \%$ de la investigación se centra en las ciencias de la salud, humana y social aplicada. En el análisis general, el fútbol produce un conocimiento científico sólido con la recurrencia y la fragmentación.
\end{abstract}

Palabras clave: Fútbol. Conocimientos. Tesis. Disertaciones. 


\section{Referências}

ANDRADE, D. C. T. de; RAMOS, H. R. Futebol Paixão Ou Negócios? Uma Análise da Produção Científica Mundial. Podium: Sport, Leisure and Tourism Review, São Paulo, v. 4, n. 3, p. 169-184, 09 nov. 2015.

CADAMURO, L. História da educação no Brasil: um estudo bibliométrico de teses e dissertações. 2011. 118 f. Dissertação (Mestrado em Educação) - Curso de Educação, Universidade Federal de São Carlos, São Carlos, São Paulo, 2011.

CAPES - Coordenação de Aperfeiçoamento de Pessoal de Nível Superior. As áreas de avaliação. 2012. Disponível em: < $\underline{\text { http://www.capes.gov.br/avaliacao/instrumentos-de-apoio/ta- }}$ bela-de-areas-do-conhecimento-avaliacao >. Acesso em: 15 out. 2015. nov. 2014.

Banco de Teses. 2014. Disponível em: <http://www.capes.gov.br>. Acesso em: 06

GEOCAPES. 2014. Disponível em: <http://geocapes.capes.gov.br/geocapes2/>. Acesso em: 15 out. 2015.

CARVALHO, S. T. Pesquisa-ação em ciências da saúde: bibliometria e análise conceitual em teses e dissertações da Universidade de São Paulo. 2012. 206 f. Tese (Doutorado em Enfermagem Psiquiátrica) - Curso de Enfermagem Psiquiátrica, Universidade de São Paulo, São Paulo, 2012.

COUTINHO, R. X. et al. Análise da produção de conhecimento da Educação Física brasileira sobre o cotidiano escolar. RBPG, Brasília, v. 9, n. 17, p. 491-516, 01 jan. 2012. Disponível em: <http://ojs.rbpg.capes.gov.br/index.php/rbpg/article/viewFile/300/283>. Acesso em: 20 fev. 2015.

GIGLIO, S. S.; SPAGGIARI, E. A produção das ciências humanas sobre futebol no Brasil: um panorama (1990-2009). História, São Paulo, n. 163, p. 293-350, jul. 2010.

GIULIANOTTI, R. Sociologia do futebol. Dimensões históricas e socioculturais do esporte das multidões. São Paulo: Nova Alexandria, 2002.

IGAMI, M. P. Z. Análise bibliométrica da produção científica de um instituto público de pesquisas. 2011. $180 \mathrm{f}$. Tese (Doutorado em Tecnologia Nuclear) - Curso de Tecnologia Nuclear, Universidade de São Paulo, São Paulo, 2011.

MADEIRA, M. O. A produção do conhecimento em Educação Física escolar no Brasil (2001-2010). 2012. 177 f. Dissertação (Mestrado em Educação Física) - Curso de Educação Física, Universidade Federal de Viçosa, Viçosa, Minas Gerais, 2012.

MEGID NETO, J.; PACHECO, D. Pesquisa em ensino de física do $2^{\circ}$ grau no Brasil concepção e tratamento de problemas em teses e dissertações. Pesquisas em ensino de Física, São Paulo, v. 2, p. 15-30, 2001.

MIRANDA, E. M. Tendências e perspectivas da ciência, tecnologia e sociedade nas áreas de Educação e ensino de ciências: uma análise a partir de teses e dissertações brasileiras e 
portuguesas. 2012. 270 f. Tese (Doutorado em Educação) - Curso de Educação, Universidade Federal de São Carlos, São Carlos, São Paulo, 2012.

NASCIMENTO, R. P.; SANTIAGO, R. A. Produção do conhecimento científico e formação de professores: uma análise do processo e suas perspectivas. In: SEMINÁRIO HISPANO BRASILEIRO, 2, 2012, São Paulo. Anais do II Seminário Hispano Brasileiro. São Paulo: Universidade Cruzeiro do Sul, 2012. p. 369-376. Disponível em: <http://revistapos.cruzeirodosul.edu.br/index.php/rencima/article/viewFile/414/347>. Acesso em: 17 mar. 2015.

NEBREDA, X. et al. Producción científica sobre fútbol en revistas españolas de ciencias de la actividad física y del deporte. Movimento, Porto Alegre, v. 21, n. 3, p. 659-672, 01 set. 2015.

OLIVEIRA, M. R. Produção de conhecimento científico: pós-graduação interdisciplinar (stricto sensu) na interface sociedade-natureza. 2011. 169 f. Tese (Doutorado em Educação) Curso de Educação, Universidade Federal do Rio Grande do Sul, Porto Alegre, 2012.

SACARDO, M. S. Estudo bibliométrico e epistemológico da produção científica em Educação Física na região Centro-Oeste do Brasil. 2012. 255 f. Tese (Doutorado em Educação) - Curso de Educação, Universidade Federal de São Carlos, São Carlos, São Paulo, 2012.

SANTOS, J. M. C. M.; DRUMOND, M. A construção de histórias do futebol no Brasil (1922 a 2000): reflexões. Tempo, São Paulo, v. 17, n. 34, p. 19-31, 24 set. 2012.

SILVA, M. R. da; HAYASHI, C. R. M.; HAYASHI, M. C. P. I. Análise bibliométrica e cientométrica: desafios para especialistas que atuam no campo. Revista Cienciometria e Infometria, Ribeirão Preto, v. 2, n. 1, p. 110-129, 2011.

SOUZA, J. de; ALMEIDA, B. S. de; MARCHI JÚNIOR, W. Por uma reconstrução teórica do futebol a partir do referencial sociológico de Pierre Bourdieu. Revista Brasileira de Educação Física, São Paulo, v. 28, n. 2, p. 221-232, jun. 2014.

VIEIRA, R. Produção científica brasileira sobre terceiro setor: uma análise bibliométrica e cienciométrica baseada no banco de teses da CAPES. 2011. 168 f. Dissertação (Mestrado) Curso de Ciência da Informação, Universidade Federal de Santa Catarina, Florianópolis, 2012.

Recebido em: 09/11/2016

Revisado em: 08/11/2017

Aprovado em: 01/02/2018

Endereço para correspondência:

alex.cbf@ufsc.br

Alex Fensterseifer

Universidade Federal de Santa Catarina,

Centro de Desportos, Departamento de Educação Física.

Campus Universitário

Trindade

88040-900 - Florianópolis, SC - Brasil 